OLIVEIRA, RJP; GATIBONI, LC; BRUNETTO, G; MIQUELLUTI, DJ; VALICHESKI, RR. 2017. Resposta da beterraba a adubação com nitrogênio, enxofre e micronutrientes em um Cambissolo Háplico. Horticultura Brasileira 35: 063-068. DOI - http://dx.doi.org/10.1590/S0102-053620170110

\title{
Resposta da beterraba a adubação com nitrogênio, enxofre e micronutrientes em um Cambissolo Háplico
}

\author{
Robinson JP Oliveira' ${ }^{1}$; Luciano C Gatiboni' ${ }^{1}$ Gustavo Brunetto ${ }^{2}$; David J Miquelluti'; Romano R \\ Valicheski $^{3}$ \\ 'Universidade do Estado de Santa Catarina (UDESC), Rio do Sul-SC, Brasil; robijpo34@hotmail.com; lgatiboni@gmail.com; a2djm@ \\ cav.udesc.br; ${ }^{2}$ Universidade Federal de Santa Maria (UFSM), Santa Maria-RS, Brasil; brunetto.gustavo@gmail.com; ${ }^{3}$ Instituto Federal \\ Catarinense (IFC), Rio do Sul-SC, Brasil; romano.valicheski@ifc.edu.br
}

\section{RESUMO}

Há poucos trabalhos no Brasil para calibrar a adubação de macro e micronutrientes para a cultura da beterraba na Região Sul do país. Neste trabalho, foram conduzidos dois experimentos, um a campo e um em casa-de-vegetação com os objetivos de: a) em condições de campo avaliar a resposta da beterraba a doses de nitrogênio $(\mathrm{N})$, na presença ou ausência de dose única dos nutrientes enxofre $(\mathrm{S})$, boro (B), zinco (Zn) e molibdênio (Mo); b) em casa-de-vegetação avaliar a resposta das plantas aos nutrientes S, B, Zn e Mo. O experimento 1 foi conduzido em um Cambissolo Háplico, com $270 \mathrm{~g} / \mathrm{kg}$ de argila e $33 \mathrm{~g} / \mathrm{kg}$ de matéria orgânica. Os tratamentos foram constituídos de doses de $\mathrm{N}(0,50,100,150$ e $200 \mathrm{~kg} /$ ha de $\mathrm{N})$ na presença ou ausência de adubação com S, Zn, B e Mo nas doses $50 ; 2 ; 1$ e $0,01 \mathrm{~kg} / \mathrm{ha}$, respectivamente, em esquema fatorial $5 \times 2$ e delineamento em blocos ao acaso, com quatro repetições. No experimento 2 usou-se o mesmo solo do experimento 1, em casa-de-vegetação em vasos de 3,0 kg de solo. Foram testados seis tratamentos (testemunha, adição de $\mathrm{S}$, de B, de Zn, ou de Mo e adição mista de S, Zn, B e Mo), em delineamento inteiramente casualisado com cinco repetições. As doses dos nutrientes testados foram as mesmas usadas no experimento 1 , e os demais nutrientes ( $\mathrm{P}$ e K ) foram adicionados em todos tratamentos seguindo as recomendações técnicas da cultura. Aos 60 dias após o transplante, as plantas de ambos experimentos foram colhidas e separadas em folhas e raízes para a determinação da matéria fresca e seca e determinação de N, S, B e Zn no tecido vegetal. Houve efeito significativo para o fator $\mathrm{N}$ com as plantas atingindo a máxima produtividade com aplicação de $100 \mathrm{~kg} /$ ha de $\mathrm{N}$, na presença de $\mathrm{S}, \mathrm{Zn}$, $\mathrm{B}$ e Mo, cuja adição praticamente dobrou a produção de raízes. $\mathrm{O}$ experimento em casa-de-vegetação comprovou que o enxofre foi o responsável pelo aumento da produção observada no experimento 1 .

Palavras-chave: Beta vulgaris, calibração, nutrição mineral, produção.

\begin{abstract}
Response of beet fertilization with nitrogen, sulfur and micronutrients in a Cambisol

There are few studies in Brazil aiming to calibrate fertilization of macro and micronutrients for beet in Southern Brazil. Two experiments were carried out, one in the field and another in a greenhouse with the objectives: a) under field conditions, to access the response of beet to nitrogen $(\mathrm{N})$ in the presence or absence of a single rate of sulfur (S), boron (B), zinc (Zn) and molybdenum (Mo); b) in a greenhouse experiment to evaluate the response of plants to $\mathrm{S}, \mathrm{B}, \mathrm{Zn}$ and Mo. The experiment 1 was carried out in a Cambisol with $270 \mathrm{~g} / \mathrm{kg}$ clay and $33 \mathrm{~g} / \mathrm{kg}$ organic matter. Treatments were $\mathrm{N}$ rates $(0,50,100,150$ and $200 \mathrm{~kg} / \mathrm{ha} \mathrm{N})$ in presence or absence of fertilization with S, Zn, B and Mo in dosages of 50;2;1 and $0.01 \mathrm{~kg}$ / ha, respectively, in a $5 \times 2$ factorial design with randomized blocks and four replications. In experiment 2 we used the same soil of experiment 1, in a greenhouse in pots of $3.0 \mathrm{~kg}$ soil. Six treatments were tested: (control, addition of $\mathrm{S}$, of $\mathrm{B}$, of $\mathrm{Zn}$, or of Mo and addition of $\mathrm{S}, \mathrm{Zn}$, $\mathrm{B}$ and $\mathrm{Mo}$ ) in a completely randomized design with five replications. The rates of nutrients were the same as used in experiment 1 , while the remaining nutrients $(\mathrm{P}$ and $\mathrm{K}$ ) were added in all treatments following the technical recommendations for the crop. At 60 days after transplantation, the plants of both experiments were collected and separated in leaves and roots for the determination of fresh and dry matter and determination of N, S, B and $\mathrm{Zn}$ in plant tissue. We observed a significant effect for factor $\mathrm{N}$ on plants reaching maximum productivity with the application of $100 \mathrm{~kg} / \mathrm{ha} \mathrm{N}$ in the presence of $\mathrm{S}, \mathrm{Zn}, \mathrm{B}$ and Mo, whose addition nearly doubled the production of roots. The experiment in the greenhouse showed that sulfur was the nutrient, after $\mathrm{N}$, responsible for increasing the production observed in experiment 1 .
\end{abstract}

Keywords: Beta vulgaris, calibration, mineral nutrition, production.

(Recebido para publicação em 23 de julho de 2015; aceito em 18 de fevereiro de 2016) (Received on July 23, 2015; accepted on February 18, 2016)

\begin{abstract}
A beterraba (Beta vulgaris) pertencente à família das Quenopodiáceas é originária de regiões européias e norte-africanas de clima
\end{abstract}

temperado (Filgueira, 2012). Em Santa Catarina, a inserção da cultura vem merecendo destaque na região do Alto Vale do Itajaí-SC, principalmente após a colheita da cebola, por apresentar um pacote tecnológico de menor custo e um ciclo bastante curto (Duarte et al., 2012). O volume médio comercializado 
desta hortaliça via CEASA/SC é de 3.600 t/ano, movimentando a cifra de aproximadamente $\mathrm{R} \$ 4,00$ milhões/ano (CEASA/SC, 2007).

Dentre os nutrientes mais exigidos pela cultura da beterraba destaca-se o nitrogênio $(\mathrm{N})$, pela sua contribuição para o aumento da produtividade, por promover a expansão foliar e acúmulo de massa de folhas e raízes (Tivelli et al., 2011). Devido à sua alta exigência e instabilidade no solo, via de regra, as adubações nitrogenadas para as culturas não leguminosas se dão em altas doses (CQFS-RS/SC, 2004), sendo levemente atenuadas em solos com altos teores de matéria orgânica (MOS), onde a MOS pode contribuir com parte do N necessário pela cultura.

O enxofre é essencial para a produção de proteínas e clorofila e, ainda é componente de alguns hormônios da planta, que melhoram o crescimento das raízes e aumentam a produtividade (Mendonça \& Peixoto, 1991). A omissão de enxofre no cultivo da beterraba afeta negativamente o número de folhas, a matéria seca da raiz e a matéria seca da planta inteira (Alves et al., 2008). Embora as plantas sejam aptas a absorver $\mathrm{S}$ via foliar, elas obtêm a maior proporção desse nutriente via radicular. A importância da aplicação do enxofre em culturas agrícolas tem sido evidenciada pela redução de sua disponibilidade aos vegetais (deficiência de $\mathrm{S}$ em muitas regiões), verificada principalmente pelo uso de fertilizantes concentrados em NPK (Maximo et al., 2005) e em solos com baixos teores de MOS.

Os micronutrientes zinco ( $\mathrm{Zn}$ ) e boro (B) são fundamentais para o crescimento e o desenvolvimento dos cultivos, agindo como constituintes das paredes celulares (B) e das membranas celulares $(\mathrm{B}, \mathrm{Zn})$ e como ativadores de enzimas (Zn) (Kirkby \& Römheld, 2007). O molibdênio (Mo) tem sido recomendado para a cultura em aplicações foliares, auxiliando supostamente no metabolismo do nitrogênio, sendo ligado à ação ou ativação enzimática principalmente das enzimas nitrogenase e redutase do nitrato (Marschner, 1995). Contudo, na literatura, estudos abrangendo Zn e Mo na nutrição da cultura da beterraba são incipientes. Na beterraba, o B aumenta a taxa de transporte de açúcares, os quais são produzidos pela fotossíntese nas folhas maduras (Allen \& Pilbeam, 2007).

Tendo em vista o exposto, fica evidente a importância do nitrogênio, enxofre, boro e zinco para a cultura da beterraba; e diante da carência de pesquisas, se fazem necessários estudos sobre os aspectos nutricionais, visando estabelecer as curvas de resposta, acúmulo e exportação de nutrientes pela cultura nos Cambissolos Háplicos do Alto Vale do Itajaí. O trabalho foi conduzido com os seguintes objetivos: a) em condições de campo, avaliar a resposta da beterraba a doses de $\mathrm{N}$, na presença ou ausência de dose única dos nutrientes S, B, Zn e Mo; b) em casa-devegetação, avaliar a resposta das plantas aos nutrientes S, B, Zn e Mo.

\section{MATERIAL E MÉTODOS}

Dois experimentos, um a campo e o outro em casa-de-vegetação, foram realizados no Instituto Federal Catarinense, em Rio do Sul-SC (27 $12^{\prime}$ '51'S, 49³8'35”O, $690 \mathrm{~m}$ de altitude). A região, segundo a classificação climática de Köppen, possui clima Mesotérmico Úmido - Cfa (sem estação seca), com verões quentes, apresentando temperaturas médias de $19,2^{\circ} \mathrm{C}$ e precipitação média anual entre 1.300 e $1.400 \mathrm{~mm}$. Quanto ao volume de precipitação e distribuição no período, ocorreram 196 $\mathrm{mm}$ de chuvas, bem distribuídas ao longo dos 60 dias em que a cultura da beterraba permaneceu a campo; volume este considerado normal para a época na região.

Nos dois experimentos utilizou-se a cultivar Early Wonder, tradicionalmente cultivada na região em estudo; A cultivar é precoce, possui raízes globulares e coloração púrpura (interna e externamente). As mudas foram produzidas em bandejas de poliestireno expandido, sendo usado substrato comercial específico para hortaliças composto à base de casca de pinus compostada, Trichoderma e vermiculita, livres de patógenos, nematóides, sementes de plantas daninhas e com alta capacidade de retenção de umidade. Foram adicionadas de 2 a 3 sementes por células e aos 8 dias após a semeadura, as plantas foram repicadas, permanecendo uma planta por célula. $\mathrm{O}$ sistema de irrigação automatizado por nebulização foi acionado três vezes ao dia, com 15 minutos de molhamento. As bandejas permaneceram sobre bancadas em casa-de-vegetação até 30 dias após a semeadura, quando foram transplantadas para os experimentos.

No experimento de campo, o solo da área experimental é um Cambissolo Háplico, com os seguintes atributos químicos: argila $270 \mathrm{~g} / \mathrm{kg}$; matéria orgânica 33 g/kg; pH em água 5,2; índice SMP 5,7; Ca, Mg e Al trocáveis (ambos extraídos por $\mathrm{KCl} 1 \mathrm{~mol} / \mathrm{L})$ 4,1, 2,3 e $0,0 \mathrm{cmol}_{\mathrm{c}} / \mathrm{dm}^{3}$, respectivamente; P disponível e K trocável (ambos extraídos por Mehlich-1) 12,6 e 66,0 mg/ $\mathrm{dm}^{3}$, respectivamente; Teor de $\mathrm{S}$ de $6,79 \mathrm{mg} /$ $\mathrm{dm}^{3}, \mathrm{Zn}$ de $13,72 \mathrm{mg} / \mathrm{dm}^{3}$ e de B de 0,11 $\mathrm{mg} / \mathrm{dm}^{3}$. O solo possuía $\mathrm{CTC}_{\mathrm{pH} 7,0}$ de $12,1 \mathrm{cmol}_{\mathrm{c}} / \mathrm{dm}^{3}$ e saturação por bases de 54,5\%. Em dezembro de 2011 foram adicionadas 5,2 t/ha de calcário (PRNT= 92\%) na superfície do solo, seguido de incorporação até a profundidade de 20 $\mathrm{cm}$, para elevar o pH em água do solo até 6,0. Três meses depois da calagem foram aplicados $380 \mathrm{~kg} /$ ha de $\mathrm{P}_{2} \mathrm{O}_{5}$ (superfosfato triplo) e $180 \mathrm{~kg} / \mathrm{ha}$ de $\mathrm{K}_{2} \mathrm{O}$ (cloreto de potássio) e incorporados ao solo até aproximadamente $20 \mathrm{~cm}$.

Os tratamentos consistiram de doses de $\mathrm{N}(0,50,100,150$ e $200 \mathrm{~kg} /$ ha de $\mathrm{N})$ usando uréia como fonte, na presença ou ausência de adubação com $\mathrm{S}, \mathrm{Zn}$, B e Mo (doses de 50; 2; 1 e $0,01 \mathrm{~kg}$ / ha, respectivamente). $\mathrm{O}$ experimento foi instalado em esquema fatorial $5 \times 2$, usando o delineamento blocos ao acaso, com quatro repetições. Os canteiros com 1,0 $\mathrm{m}$ de largura e 6,4 $\mathrm{m}$ de comprimento foram preparados mecanicamente e subdivididos em parcelas onde os tratamentos foram aplicados na superfície do solo e incorporados usando um rastelo até, aproximadamente, $10 \mathrm{~cm}$ de profundidade. Em fevereiro de 2012, após a aplicação do fósforo, potássio e $33 \%$ da dose de $\mathrm{N}$ referente a cada tratamento, as mudas de beterraba foram transplantadas, em um espaçamento de $25 \mathrm{~cm}$ entre linhas e $8 \mathrm{~cm}$ entre plantas. $O$ restante da adubação nitrogenada foi aplicado em cobertura aos 20 e 40 dias após o transplante. As fontes de $\mathrm{S}, \mathrm{Zn}$, 
B e Mo utilizadas foram S puro (95\%), $\mathrm{ZnSO}_{4}(20 \%$ de $\mathrm{Zn}), \mathrm{H}_{3} \mathrm{BO}_{3}(17,4 \%$ de B) e $\mathrm{MoO}_{3}(57 \%$ de Mo), sendo que a fertilização com Mo foi realizada via foliar, com aplicações semanais. Em cada parcela experimental cultivou-se 16 plantas (4 linhas de 4 plantas), das quais, apenas coletou-se para avaliação 4 plantas localizadas no centro de cada parcela, sendo as demais consideradas bordadura.

Para o experimento de casa-de-vegetação, foram coletadas amostras de solo do experimento de campo, seca ao ar, destorroadas e passadas em peneira com malha de $2 \mathrm{~mm}$. Em seguida, o solo foi dividido em porções de $3 \mathrm{~kg}$, acondicionado em sacos plásticos e armazenado em vasos. Foram testados seis tratamentos: testemunha, adição de $\mathrm{S}$, adição de $\mathrm{Zn}$, adição de $\mathrm{B}$, adição de Mo além de um tratamento completo com todos os nutrientes. O delineamento experimental foi inteiramente casualizado, com cinco repetições. Aplicou-se $50 \mathrm{~kg} / \mathrm{hade} \mathrm{S}$ ( $25 \mathrm{mg} / \mathrm{kg}$ de solo), $2 \mathrm{~kg} /$ ha de B (1 mg/kg de solo), $10 \mathrm{~kg} / \mathrm{ha} \mathrm{de}$ $\mathrm{Zn}(5 \mathrm{mg} / \mathrm{kg}$ de solo) e $0,01 \mathrm{~kg} / \mathrm{ha}$ de Mo $(0,005 \mathrm{mg} / \mathrm{kg}$ de solo $)$ a partir das seguintes fontes: para $\mathrm{Zn}$ utilizou-se $\mathrm{Zn}(\mathrm{Cl})_{2}(47,98 \%$ de $\mathrm{Zn})$, para o B foi utilizado $\mathrm{H}_{3} \mathrm{BO}_{3}(17,4 \%$ de $\mathrm{B})$, para $\mathrm{S}$ utilizou-se $\mathrm{S}$ puro $(95 \%$ de $\mathrm{S})$ e para Mo foi usado $\mathrm{MoO}_{3}(57 \%$ de Mo). As fontes dos nutrientes foram aplicadas na superfície do solo contido no vaso e homogeneizado. Para o Mo, uma grama de $\mathrm{MoO}_{3}(57 \%)$ foi diluída em um litro de água e pulverizado via foliar, semanalmente, após o transplante das mudas.

Em novembro de 2012 em cada vaso foi transplantada uma muda de beterraba, sendo cultivada até os 60 DAT (dias após o transplante). Ao longo do cultivo a umidade do solo foi mantida a $80 \%$ da capacidade de campo, através de pesagens diárias e, quando necessário foi adicionado água.

Para os dois experimentos, aos 60 dias após o transplante (DAT), as plantas foram colhidas e determinou-se o diâmetro de raiz com o auxílio de um paquímetro; após, as folhas foram separadas da raiz e determinado a matéria fresca de folhas e raiz de cada planta. As folhas e a raiz de cada planta foram acondicionadas individualmente em sacos de papel e secas em estufa com circulação de ar forçado a $65^{\circ} \mathrm{C}$, até atingir peso constante. Em seguida, determinou-se a matéria seca de folhas e raiz, usando balança digital. As folhas e raízes foram moídas, preparadas e uma porção foi submetida à digestão sulfúrica, sendo no extrato determinado o teor total de $\mathrm{N}$ pelo método de Kjeldahl (Tedesco et al., 1995). Outra porção foi submetida à digestão nitroperclórica, e no extrato determinado $\mathrm{S}$, pelo método de turbidimetria, e Zn, por espectrofotometria de absorção atômica (Tedesco et al., 1995). Uma última porção foi digerida em mufla a $600^{\circ} \mathrm{C}$ por $60 \mathrm{~min}$, sendo no extrato, por colorimetria determinado o B (Tedesco et al., 1995). Esta metodologia foi aplicada em todas as amostras nos dois experimentos.

Os resultados do experimento 1 foram submetidos à análise de variância, considerando um fatorial com 5 doses de $\mathrm{N}$ e dois níveis de nutrientes complementares ( $\mathrm{S}, \mathrm{Zn}$, Mo e B), usando o pacote estatístico SAS, versão 9.1.3 (SAS Institute, 2006). Quando detectado efeito significativo para as doses de $\mathrm{N}$ foram testados os modelos linear, quadrático e linear-platô, adotando-se o de maior significância e sentido agronômico. Para isso, foi usado o pacote estatístico

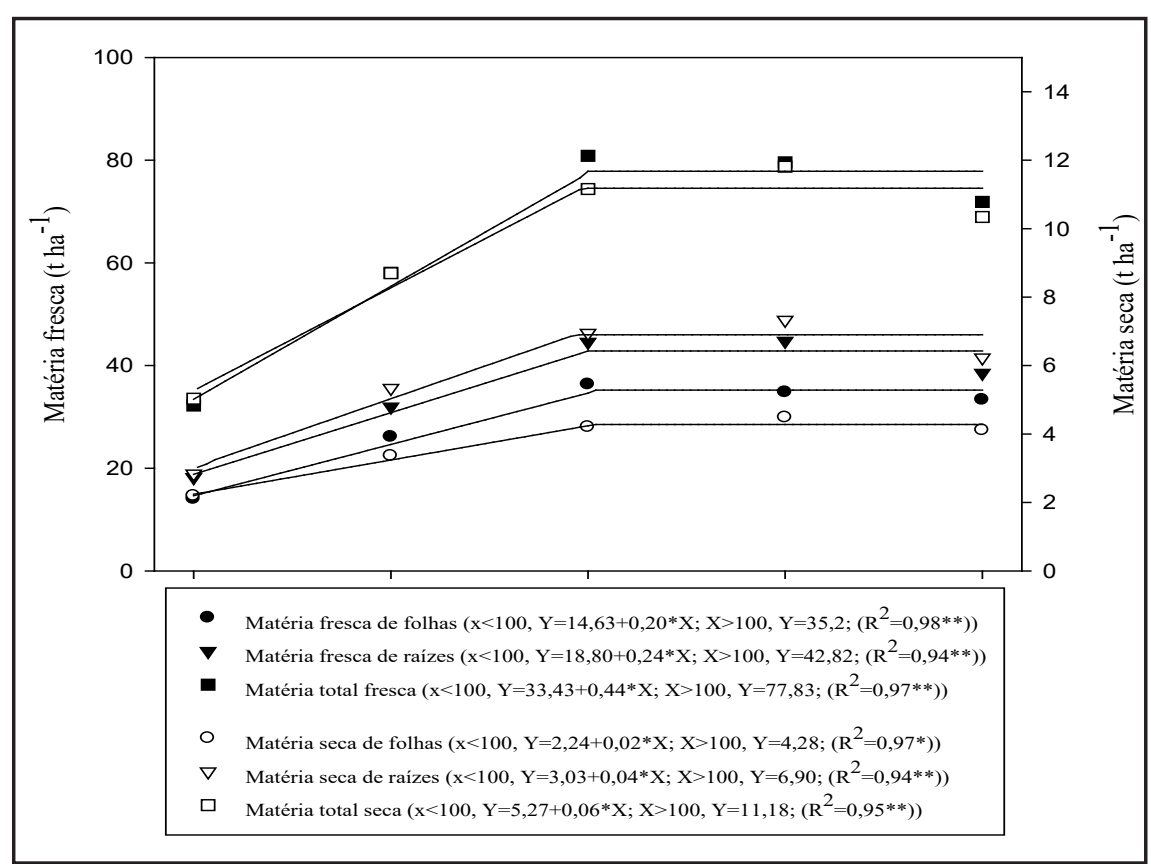

Figura 1. Matéria seca e fresca de folha, raiz e total em função da dose de $\mathrm{N}$ aplicado no cultivo de beterraba (dry and fresh matter of leaf, root and total on beet plants, depending on applied N dose). Lages, UDESC, 2014.
SAS, versão 9.1.3 (SAS Institute, 2006) e os procedimentos recomendados por Anderson \& Nelson (1974).

Os resultados do experimento 2 foram submetidos à análise de variância e quando significativo, as médias foram comparadas pelo Teste de Tukey a 5\% de probabilidade de erro, utilizando-se o programa SASm (Canteri et al., 2001).

\section{RESULTADOS E DISCUSSÃO}

Para o fator dose de N, houve efeito significativo $(\mathrm{p}<0,01)$ para todas as variáveis biométricas avaliadas [matéria fresca de folha (MFF), matéria seca de folha (MSF), matéria fresca de raiz (MFR), matéria seca de raiz (MSR), matéria fresca total (MFT) e matéria seca total (MST)] (Figura 1). Os resultados positivos obtidos para a dose de $\mathrm{N}$ se devem ao papel funcional do $\mathrm{N}$ no metabolismo de desenvolvimento da beterraba. O N é encontrado em compostos orgânicos como aminoácidos e ácidos nucleicos e participa de diversos processos fisiológicos vitais para a vida das plantas, como a absorção iônica, fotossíntese, respiração celular, multiplicação e diferenciação celular (Epstein \& Bloom, 2006). 
Com a adição de $\mathrm{N}$ ao solo, espera-se um aumento do teor de $\mathrm{N}$ mineral no solo (nitrato e amônio), que por sua vez chega às raízes basicamente por fluxo de massa, e é absorvido pelas plantas principalmente na forma de $\mathrm{NO}_{3}^{-}$, podendo ser reduzido ou armazenado nos vacúolos, ou translocado para a parte aérea via xilema, onde será reduzido ou armazenado nos vacúolos foliares. Uma vez assimilado, o $\mathrm{NO}_{3}$ - é translocado via floema até os sítios de absorção, tendo papel fundamental no metabolismo vegetal, sendo essencial para a estrutura e funções nas células, para as reações enzimáticas, e fazendo parte da molécula de clorofila (Taiz \& Zeiger, 2004).

Os resultados obtidos para as variáveis biométricas vêm ao encontro com os relatados por Aquino et al. (2006). Estes autores comentam que a aplicação de 0, 100, 200 e 400 kg/ha de $\mathrm{N}$ para a cultura da beterraba, em um Argissolo Vermelho Amarelo com 32 g/ $\mathrm{dm}^{3}$ de M.O. promoveu incremento até certo ponto em todas as características avaliadas (MFR, MFF, MSR e MSF). A produção de matéria seca de parte aérea e raiz de beterraba aumentou com a aplicação de diferentes doses de $\mathrm{N}$, apresentando resposta linear e crescente, sendo que normalmente as maiores produtividades de raízes de beterraba são obtidas com as maiores doses de $\mathrm{N}$ (Purquerio et al., 2009).

Quando a fonte de variação foi a presença ou ausência de adubação composta por $\mathrm{S}+\mathrm{Zn}+\mathrm{B}+\mathrm{Mo}$, houve efeito significativo $(\mathrm{p}<0,01)$, sendo que em praticamente todos os parâmetros testados, o uso desses nutrientes praticamente dobrou a produção em relação aos tratamentos sem a aplicação dos mesmos (Figura 1). Foram observados aumentos de 1,70 vezes para MSF; 2,19 vezes para MSR; 2,0 vezes para MST; 2,0 vezes para MFF; 2,33 vezes para MFR e 2,17 vezes para MFT. É possível que o teor dos nutrientes em questão no solo fosse insuficiente para suprir a demanda das plantas de beterraba. Por isso, quando aplicados, resultaram em aumento da produção. Os micronutrientes são limitantes ao crescimento das culturas, sendo que o nível adequado destes na planta é essencial para a obtenção do uso eficiente de

Tabela 1. Acúmulo de $\mathrm{N}(\mathrm{kg} / \mathrm{ha})$ em folhas, raízes e $\mathrm{N}$ extraído na planta em função das diferentes doses de $\mathrm{N}$ (fator 1), dois níveis do mix (fator 2), interação entre os fatores (F1xF2) e coeficiente de variação \{accumulation of $\mathrm{N}(\mathrm{kg} / \mathrm{ha})$ on leaves, roots and $\mathrm{N}$ extracted on the plant depending on different doses of $\mathrm{N}$ (factor 1), two levels of the mix (factor 2), interaction between the factors (F1xF2) and coefficient of variation\}. Lages, UDESC, 2014.

\begin{tabular}{lccc}
\hline \multirow{2}{*}{ Fonte de variação } & $\begin{array}{c}\text { N acumulado } \\
\text { folhas }\end{array}$ & $\begin{array}{c}\text { N acumulado } \\
\text { raízes }\end{array}$ & $\begin{array}{c}\text { N extraído na } \\
\text { planta }\end{array}$ \\
\cline { 2 - 4 } & & $\mathbf{( k g} / \mathbf{h a})$ & \\
\hline F1 (0 kg/ha) & 43,7 & 34,7 & 78,4 \\
F1 (50 kg/ha) & 75,4 & 64,3 & 139,7 \\
F1 (100 kg/ha) & 102,7 & 98,6 & 201,3 \\
F1 (150 kg/ha) & 104,5 & 110,1 & 214,6 \\
F1 (200 kg/ha) & 112,2 & 105,8 & 218,1 \\
\hline Valor de F & $7,79^{* *}$ & $7,02^{* *}$ & $8,87^{* *}$ \\
F2 (sem) & 67,12 & 62,0 & 129,1 \\
F2 (com) & 124,4 & 120,6 & 245,0 \\
Valor de F & $38,89^{* *}$ & $25,89^{* *}$ & $38,21^{* *}$ \\
Interação F1xF2 & 2,12 ns & $0,87^{\mathrm{ns}}$ & $1,60^{\mathrm{ns}}$ \\
\hline CV (\%) & 25,2 & 32,7 & 26,13 \\
\hline
\end{tabular}

$\mathrm{F} 1=$ fator $1($ dose de $\mathrm{N}) ; \mathrm{F} 2=$ fator 2 (adubação com S, Zn, Mo e B); $(\mathrm{F} 1=$ factor $1(\mathrm{~N}$ rate); $\mathrm{F} 2=$ factor 2 (fertilization with $\mathrm{S}, \mathrm{Zn}, \mathrm{Mo}$ and $\mathrm{B}$ ); ** significativo ao nível de $1 \%$ de probabilidade (significant at $1 \%$ ); ns não significativo ao nível de $5 \%$ de probabilidade (not significant at $5 \%$ ).

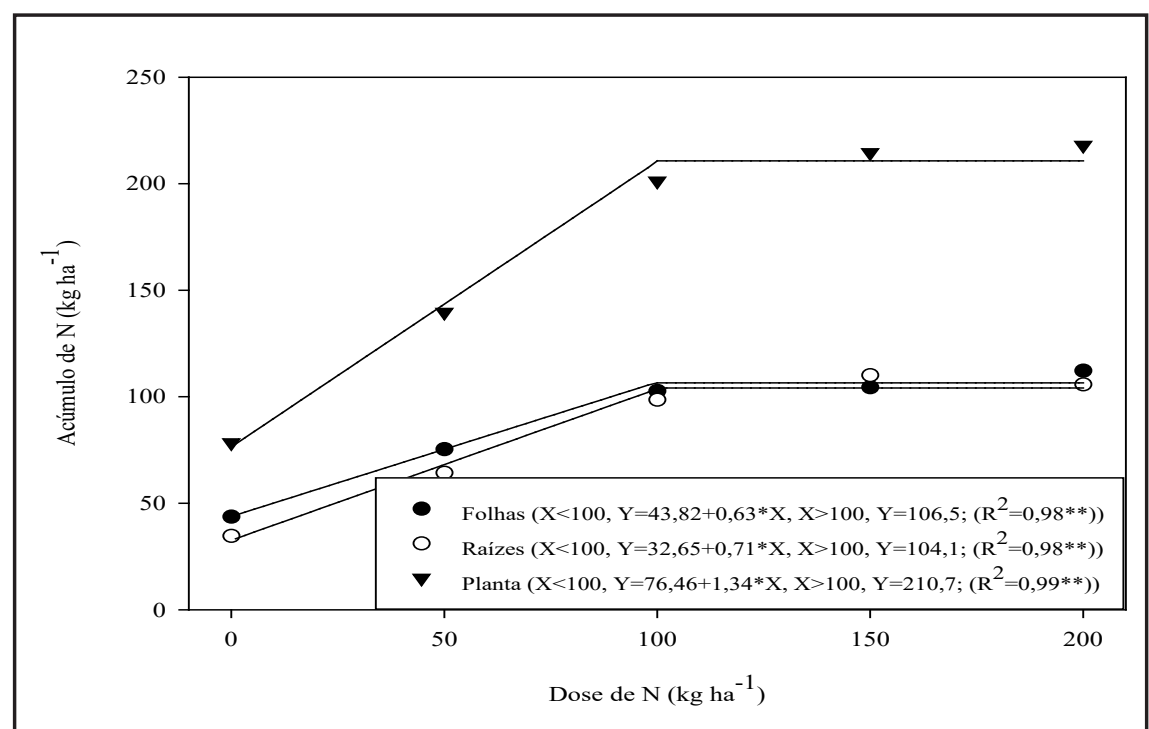

Figura 2. Nitrogênio acumulado (kg/ha) em folhas, raízes e $\mathrm{N}$ extraído em plantas de beterraba em função de doses de $\mathrm{N}(\mathrm{kg} / \mathrm{ha})$ \{accumulation of nitrogen $(\mathrm{kg} / \mathrm{ha})$ in leaves, roots and $\mathrm{N}$ extracted from beet plants depending on $\mathrm{N}$ rates $(\mathrm{kg} / \mathrm{ha})\}$. Lages, UDESC, 2014.

fertilizantes contendo N e P (Kirkby \& Romheld, 2007).

Não foi observada interação entre as doses de $\mathrm{N}$ e o uso de $\mathrm{S}+\mathrm{Zn}+\mathrm{B}+\mathrm{Mo}$, embora o uso desses nutrientes tenha aumentado a produtividade, o aumento foi semelhante em qualquer dose de $\mathrm{N}$ testada. Assim, indica-se o uso da dose de $\mathrm{N}$ que proporcione o melhor retorno técnico ou econômico, associado ao uso dos nutrientes $\mathrm{S}+\mathrm{Zn}+\mathrm{B}+\mathrm{Mo}$.

Para determinar a dose de $\mathrm{N}$ mais adequada para as condições experimentais, a figura 1 apresenta o modelo de equação linear-platô, que foi significativo $(\mathrm{p}<0,01)$ para matéria seca e fresca 
de folha, raiz e total na planta. O modelo linear-platô é um modelo segmentado, caracterizado por dois segmentos, sendo o primeiro determinado por uma resposta crescente até um determinado ponto (intersecção entre as retas) e que, a partir deste, a planta não responde ao aumento da dose de fertilizante; assim, o modelo assume um valor constante, denominado platô (Anderson \& Nelson, 1974). O ponto de intersecção entre a equação linear e o platô representa o nível ótimo de nutriente, ou nível crítico.

As plantas atingiram o platô com a dose de $100 \mathrm{~kg} / \mathrm{ha}$ de $\mathrm{N}$, indicando que esta é a dose que proporciona maior retorno econômico para o produtor, com a produção de $42,82 \mathrm{t} / \mathrm{ha}$ de raízes (equivalente ao produto beneficiado), para uma população de 500.000 plantas/ha; valor este superior ao descrito por Filgueira (2012), que destaca que a produtividade da cultura varia de 20 a 35 t/ha. ACQFS-RS/SC (2004) recomenda, para um solo com teor de matéria orgânica de $33 \mathrm{~g} / \mathrm{kg}$, a aplicação de $70 \mathrm{~kg} /$ ha de N, valor inferior aos $100 \mathrm{~kg} / \mathrm{ha} \mathrm{de}$ $\mathrm{N}$ recomendados no presente trabalho.

Avaliando o potencial de otimização econômica e ambiental da fertilização em lavouras de beterraba açucareira em uma região europeia, Caamal-Pat $e t$ al. (2014) concluiram que na maioria das áreas pesquisadas, $51,1 \%$ utilizam mais $\mathrm{N}$ do que o necessário, ou seja, em $35 \%$ das propriedades é aplicado um excedente entre 5 e $15 \%$ de $\mathrm{N}$ e, em $14,6 \%$ das propriedades aplicam-se entre 15 e $30 \%$ a mais de $\mathrm{N}$; enquanto que em $24,7 \%$ das propriedades aplicam-se menos $\mathrm{N}$ que o recomendado e, em somente $23,4 \%$ das propriedades segue-se a recomendação com base no conteúdo presente no solo e na extração pela cultura.

Os altos valores de $\mathrm{R}^{2}(\geq 0,94)$, como os verificados nas equações das Figuras 1, são considerados critérios de lógica biológica (quando verifica-se que após uma certa dose do fertilizante não ocorre acréscimo na produtividade) é indicativo da escolha correta do modelo, o qual possibilita a identificação da dose ótima econômica de N para a cultura (Silva et al., 2007).

Os valores de $\mathrm{F}$ e o nível de significância para as fontes de variação, bem

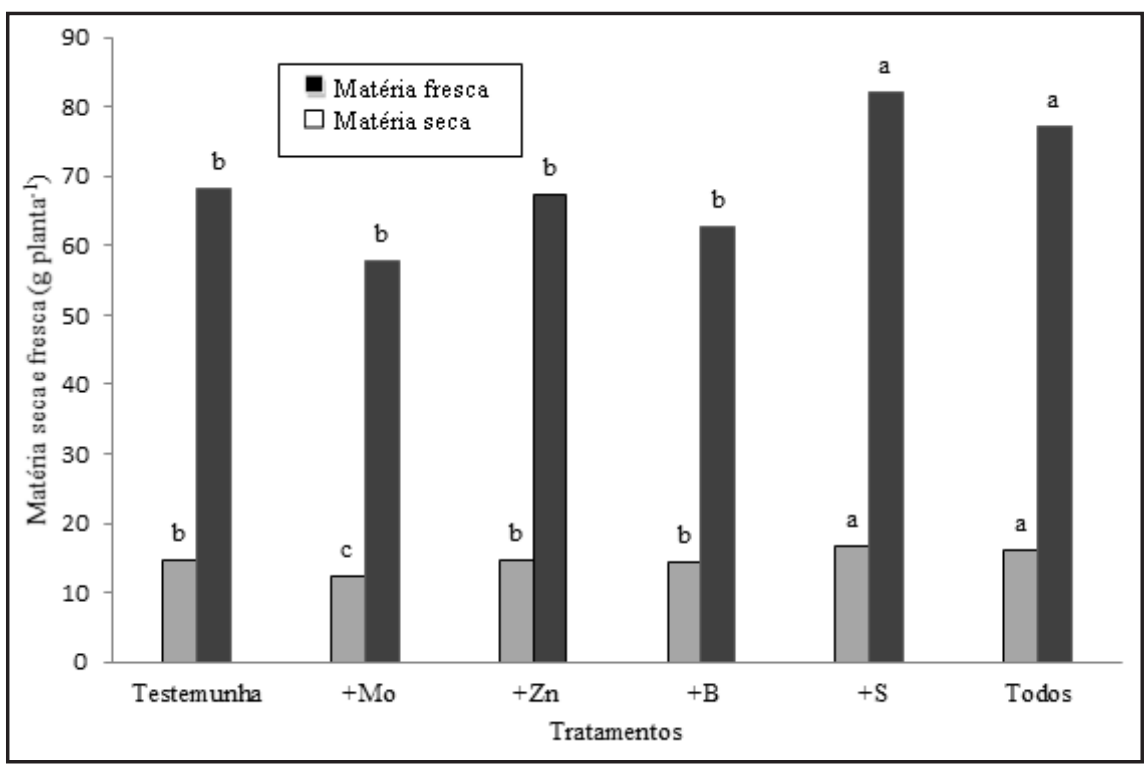

Figura 3. Matéria seca e fresca (g/planta) de raiz de beterraba para os diferentes tratamentos: $\mathrm{T}=$ testemunha; $\mathrm{Mo}=$ molibdênio; $\mathrm{B}=$ boro; $\mathrm{Zn}=$ zinco; $\mathrm{S}=$ enxofre e Todos= completo com todos os demais nutrientes; conduzido em vaso em casa de vegetação. Letras iguais não diferem entre si pelo teste de Scott-Knott a 5\% de probabilidade \{fresh and dry matter (g/plant) of beet roots depending on different treatments: $\mathrm{T}=$ control; $\mathrm{Mo}=$ molybdenum; $\mathrm{B}=$ boron; $\mathrm{Zn}=$ zinc; $\mathrm{S}=$ sulfur and Todos= complete with all other nutrients; carried out in pots in a greenhouse. Same letters do not differ by Scott-Knott, 5\% . Lages, UDESC, 2014.

como o coeficiente de variação experimental para acúmulo de $\mathrm{N}$ em folhas, raízes e $\mathrm{N}$ total extraído nas plantas de beterraba em função das diferentes doses de $\mathrm{N}$ aplicadas no solo (F1), apresentaram efeito significativo $(\mathrm{p}<0,01)$ para todas as variáveis analisadas (tabela 1 ). Para o fator interação entre F1 e F2, não houve efeito significativo, semelhante ao observado para a matéria seca e fresca de folhas e raízes.

Para uma população de 500.000 plantas/ha de beterraba, e colheita aos 60 dias após o transplante, o acúmulo máximo de nitrogênio (Figura 2) em folhas foi de $106,5 \mathrm{~kg} / \mathrm{ha}(50,6 \%) \mathrm{e}$, de $104,1 \mathrm{~kg} / \mathrm{ha}$ nas raízes $(49,4 \%)$, de um total de $210,7 \mathrm{~kg} / \mathrm{ha}$ de $\mathrm{N}$ extraído pelas plantas para a dose de $100 \mathrm{~kg} / \mathrm{ha}$ de N aplicado no solo, considerando o nível crítico estabelecido. Estes valores são bastante próximos aos obtidos por Grangeiro et al. (2007), que foi de 186,10 $\mathrm{kg} / \mathrm{ha}$ de $\mathrm{N}$ na planta, sendo que a parte aérea acumulou 98,07 kg/ha $(52,7 \%)$ e as raízes $88,03 \mathrm{~kg} / \mathrm{ha}(47,3 \%)$, para a cultivar Early Wonder, aos 60 DAS.

A eficiência no acúmulo de $\mathrm{N}$ varia em função da produção de matéria seca da parte aérea e raízes, e do teor de $\mathrm{N}$ nesses órgãos, e dependem de fatores gerenciais, ambientais e genotípicos envolvidos nos diversos processos que ocorrem na planta, como absorção e translocação de N, crescimento, desenvolvimento e partição de assimilados (Zebarth et al., 2006).

Quanto à distribuição percentual da quantidade de $\mathrm{N}$ acumulada nas raízes e parte aérea em diversos trabalhos, os resultados são contraditórios, pois em muitos casos a maior proporção de $\mathrm{N}$ está nas folhas, em outros, a maior proporção está nas raízes. Isto se deve à inversão quanto ao teor de $\mathrm{N}$ na parte aérea e raiz, e está relacionada com a época em que é feita a avaliação das plantas pois, na fase inicial (entre 40 e 50 DAS) as folhas são os drenos preferenciais e, após este período, as raízes passam a demandar mais $\mathrm{N}$, por ser este um nutriente móvel (Grangeiro et al., 2007).

Para o uso da adubação com $\mathrm{S}+\mathrm{Zn}+\mathrm{B}+$ Mo, também houve efeito significativo (acúmulo de $\mathrm{N}$ na folha, na raiz e extração total de $\mathrm{N}$ na planta). O uso de $\mathrm{S}+\mathrm{Zn}+\mathrm{B}+\mathrm{Mo}$ promoveu aumentou de 1,85 vezes no acúmulo de $\mathrm{N}$ via folhas; 1,95 vezes o $\mathrm{N}$ em raízes e 1,90 vezes a extração total de $\mathrm{N}$ pela planta. É possível que este aumento 
no acúmulo de $\mathrm{N}$ tenha ocorrido em função do $\mathrm{S}$, uma vez que este nutriente é necessário em quantidades razoáveis pelas plantas para a síntese dos aminoácidos essenciais metionina e sisteina, e para produzir as proteínas estruturais e funcionais; atuando também junto ao grupo funcional de coenzimas, tornando mais eficiente a síntese de proteínas (Willenbrink, 1967). Seadh et al. (2007) citam que a aplicação de enxofre aumentou significativamente o conteúdo de nitrogênio devido ao seu efeito no aumento das atividades em nitrato redutase e nitrito redutase no solo, consequentemente, aumentou a disponibilidade de nutrientes na rizosfera, juntamente com o aumento da atividade em nível celular, e provavelmente, aumentou a absorção de $\mathrm{N}$ e sua concentração nos órgãos das plantas de beterraba.

Para confirmar qual(is) dos nutrientes aplicados no experimento de campo foram responsáveis pelo aumento da produtividade, foi realizado o experimento de casa-de-vegetação, cujos resultados são apresentados na Figura 3. A beterraba cultivada no solo contendo o tratamento "Todos" (presença de S, B, Zn e Mo) e o tratamento $+\mathrm{S}$ (presença de enxofre) apresentou maior produção de matéria seca e fresca de raiz. Os tratamentos $+\mathrm{Mo},+\mathrm{Zn}$ e $+\mathrm{B}$ (presença de molibdênio, zinco e boro, respectivamente) não diferiram da testemunha, indicando que a adição destes nutrientes não promoveu aumento da produtividade no solo testado. Com isso, pode-se verificar que o $\mathrm{S}$ é o nutriente que proporcionou o aumento de produtividade no experimento de campo quando foi aplicado juntamente com o nitrogênio.

Assim, conclui-se que as plantas de beterraba cultivadas no solo com a adição de $100 \mathrm{~kg} / \mathrm{ha}$ de $\mathrm{N}$ apresentaram a maior produção de matéria fresca e seca de folhas e raízes de beterraba; e o uso de adubação com enxofre associado à adubação NPK praticamente dobrou a produção de matéria seca e fresca de folhas e raízes e o acúmulo de nitrogênio em beterraba. $\mathrm{O}$ nível crítico de $\mathrm{N}$ no tecido foliar foi de $106,5 \mathrm{~kg} / \mathrm{ha}$ obtido na dose $100 \mathrm{~kg} / \mathrm{ha}$ de $\mathrm{N}$.

\section{REFERÊNCIAS}

ALLEN, VB; PILBEAM, DJ. 2007. Handbook of plant nutrition. Books in soils, plants and the environment. Boron by Umesh C. Gupta. 241-278.

ALVES, AU; PRADO, RM; GONDIM, ARO; FONSECA, IM; CECÍLIO FILHO, AB. 2008. Desenvolvimento e estado nutricional da beterraba em função da omissão de nutrientes. Horticultura Brasileira 26: 292-295.

ANDERSON, RL; NELSON, LA. 1974. A family of models involving intersecting straight lines and concomitant experimental designs useful in evaluating response to fertilizer nutrients. Biometrics 31: 303-318. Disponível em: http:// www.jstor.org/stable/2529422>. Acessado em 23 jul. 2014. ISSN: 0006341X E-ISSN: 15410420.

AQUINO, LA; PUIATTI, M; PEREIRA, PRG; PEREIRA, FHF; LADEIRA, IR; CASTRO, MRS. 2006. Produtividade, qualidade e estado nutricional da beterraba de mesa em função de doses de nitrogênio. Horticultura Brasileira 24: 199-203.

CAAMAL-PAT, ZH; GARCIA, RAC; MENESES, BUL. 2014. Optimización econômica y ambiental de la fertilización em explotaciones de uma región europea. Revista Chapingo 20: 117-129.

CANTERI, MG; ALTHAUS, RA; VIRGENS FILHO, JS; GIGLIOTI, EA; GODOY, CV. 2001. SASM - Agri: Sistema para análise e separação de médias em experimentos agrícolas pelos métodos Scoft-Knott, Tukey e Duncan. Revista Brasileira de Agrocomputação 1: 18-24.

CEASA/SC. 2007. Estatística dos produtos comercializados na CEASA/SC - Boletim mensal/Junho de 2007. São Jose-SC. Disponível em: http://cepa.epagri.sc.gov.br/ Ceasa/BOLETIM\%20CEASA\%20JUNHO. pdf

COMISSÃO DE QUÍMICA E FERTILIDADE DO SOLO - CQFRS/SC. 2004. Manual de adubação e calagem para os estados do Rio Grande do Sul e Santa Catarina. 10.ed. Porto Alegre: Sociedade Brasileira de Ciência do Solo. 400p.

DUARTE, TS; HILLESHEIM, PC; SCHEIDT, BT. 2012. Estudo comparativo de genótipos de beterraba cultivados na primavera/verão no Alto Vale do Itajaí-SC. Horticultura Brasileira 30: S2957-S2963.

EPSTEIN, E; BLOOM, AJ. 2006. Nutrição mineral de plantas: princípios e perspectivas. 2. ed. Londrina: Planta, 403p.

FILGUEIRA, FAR. 2012. Novo manual de olericultura: agrotecnologia moderna na produção e comercialização de hortaliças. $3^{\mathrm{a}}$ edição. Viçosa: UFV. 418p.

GRANGEIRO, LC; NEGREIROS, MZ; SOUZA, BS; AZEVÊDO, PE. 2007. Acúmulo e exportação de nutrientes em beterraba. Ciência e Agrotecnologia 31: 267-273.

KIRKBY，EA；RÖMHELD，V. 2007. Micronutrientes na fisiologia de plantas: funções, absorção e mobilidade. Tradução: Suzana Oellers Ferreira. Encarte Técnico. Informações Agronômicas nº 118 .

MARSCHNER, H. 1995. Mineral nutrition of higher plants. 2. ed. New York: Academic press. $889 \mathrm{p}$.

MAXIMO, E; BENDASSOLI, JA; TRIVELIN, PCO; ROSSETE, ALRM; OLIVEIRA, CR; PRESTES, CV. 2005. Produção de sulfato de amônio duplamente marcado com os isótopos estáveis ${ }^{15} \mathrm{Ne} \mathrm{e}^{34} \mathrm{~S}$. Química Nova 28: 211-216.

MENDONÇA, ATC; PEIXOTO, N. 1991. Efeitos do espaçamento e de níveis de adubação em cultivares de batata-doce. Horticultura Brasileira 9: 80-82.

PURQUERIO, LFV; FACTOR, TL; LIMA, JRS; TIVELLI, SW; TRANI, PE; BREDAJUNIOR, JM; ROCHA, MAV. 2009. Produtividade e qualidade de beterraba cultivada em plantio direto em função do nitrogênio e molibdênio. Horticultura Brasileira 27: S366-S372.

SAS Institute. 2006. Base SAS 9.1.3 Procedures Guide SAS Ver. 9.1.3. Cary, SAS Institute Inc. 398p.

SEADH, SE; FAROUK, S; EL-ABADY, MI. 2007. Response of sugar beet to potassium sulfate under nitrogen fertilizers in newly reclaimed soils conditions. African Crop Science 8: 147-153.

SILVA, MCC; FONTES, PCR; MIRANDA, GV. 2007. Modelos estatísticos para descrever a produtividade de batata em função da adubação nitrogenada. Horticultura Brasileira 25: 360- 364.

TAIZ, L; ZEIGER, E. 2004. Fisiologia vegetal. Porto Alegre: Artmed. 719p.

TEDESCO, MJ; GIANELLO, C; BISSANI, CA; BOHNEN, H; VOLKWEISS, SJ. 1995. Análise de solo, plantas e outros materiais. Porto Alegre: UFRG, 174p.

TIVELLI, SW; FACTOR, TL; TERAMOTO, JRS; FABRI, EG; MORAES, ARA; TRANI, PE; MAY, A. 2011. Beterraba: do plantio à comercialização. Campinas: Intituto agronômico, p.45. (Boletim técnico 210).

W I L LEN B R IN K, J . 1967 . U ber Beziehungen zwischen proteinumsatz und schwefelversorgung der orasten. Pflanzenphysiolgie 56: 427-438.

ZEBARTH, BJ; ARSENAULT, WJ; SANDERSON, JB. 2006. Effect of seedpiece spacing and nitrogen fertilization on tuber yield, yield components and nitrogen use efficiency parameters of two potato cultivars. American Journal of Potato Research 83: 289-296. 